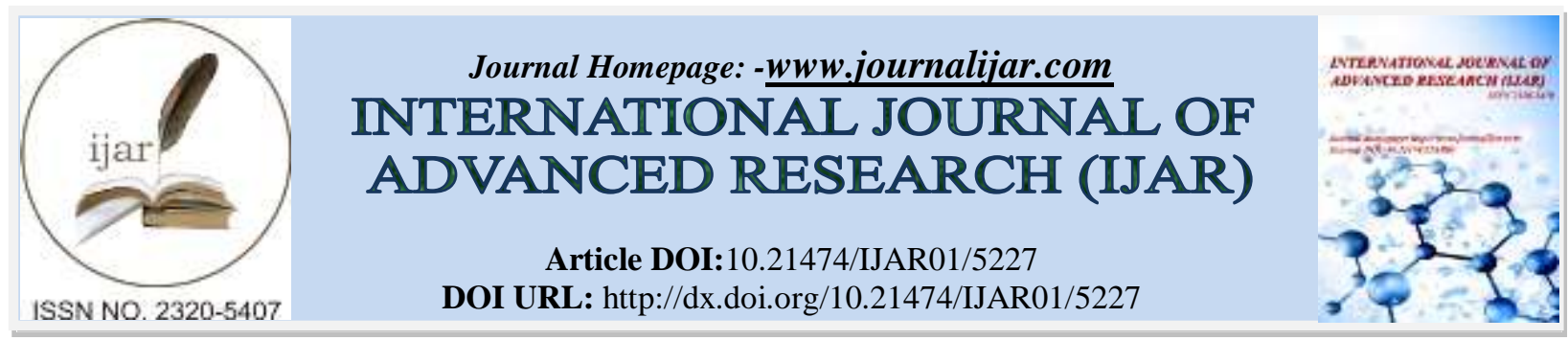

RESEARCH ARTICLE

\title{
RISK ASSESSMENT OF TOXIC HEAVY METAL POLLUTION ON AQUATIC AND HUMAN LIFE.
}

\author{
Dr. Alkesh I. Shah.
}

Associate Professor \& Head, Zoology Department, B. P. Baria Science Institute, Navsari - 396445, Gujarat, India.

\section{Manuscript Info}

(..........................

Manuscript History

Received: 20 June 2017

Final Accepted: 22 July 2017

Published: August 2017

Keywords:-

Labeorohita, industrialization, aquatic

life, heavy metals, hematology.

\section{Abstract}

In the industrialization era, pollution has deteriorated the living conditions of aquatic life leading to a steep deterioration in their quality and diversity. Industries discharge their waste containing heavy metals into the water bodies. These heavy metals accumulate in different organs of the fish, causing mortality. The effect first appears in blood and affects the fish by alteration of blood components making the fish weak, anemic and vulnerable to diseases. Heavy metal pollution thus targets fish which is one of the major protein source for human population. Such exposure to heavy metals cause increase or decrease in hematological indices of the fish coupled with decline in protein and glycogen reserves. Hence this study has been focused on the impact of heavy metals on fish Labeo rohita. Heavy metals affect the reticulo endothelial system and haematopoisis, changing osmotic resistance of erythrocytes. The red and white blood cells at different stages of the pathological process are subjected to quantitative and qualitative deformation.

Copy Right, IJAR, 2017,. All rights reserved.

\section{Introduction:-}

Heavy metal toxicity has proved to be a major threat as several health risks are associated with it. These metals have hardly any biological role to play in the human body but on the contrary their toxic effect causes malfunctioning of the body system. These elements may sometimes act as pseudo elements of the body, interfering with the metabolic processes that occur in the body. They accumulate in the body resulting into chronic diseases. In order to maintain public health, measures have been taken to control and prevent by treating metal toxicity occurring at various levels like occupational exposure, accidents and environmental factors. Metal toxicity depends on the absorbed dose, its route as well as duration of exposure. These heavy metals bind with protein sites which are not meant for them, by displacing original metals from their natural binding sites causing malfunctioning of cells by their toxicity. Oxidative deterioration of biological macromolecules is primarily due to binding of heavy metals to the DNA and nuclear proteins. Industrial waste contain large number of toxicants such as salts of heavy metals, acids, organic matter, pesticides and even cyanides which deteriorate the physiochemical characteristics of water. These pollutants build up in the food chain and are responsible for adverse effects and even death of the organisms in the aquatic system. Fish serve as biomarkers of environmental pollution as studies on the overall health are widely carried out in order to evaluate the physiological changes of aquatic ecosystems. Heavy metals are generally referred to as those metals which possess a specific density of above $5 \mathrm{gm} / \mathrm{cm}^{3}$ and adversely affect the environment and living organisms. These metals are quintessential to maintain various biochemical and physiological functions in living organisms in very low concentrations only. These metals prove to be noxious when they exceed certain threshold concentrations. Heavy metals are significant environmental pollutants and their toxicity is a problem of increasing 
significance for ecological, evolutionary, nutritional and environmental reasons. The most commonly found heavy metals in waste water include copper, nickel, zinc, cobalt and cadmium all of which cause risks for human health and environment. Heavy metal toxicity can lower energy levels and damage the functioning of brain, lungs, kidney, liver and blood composition and other important organs. Long term exposure to high concentrations lead to gradual and progressive physical, muscular and neurological degenerative processes that initiate disease like multiple sclerosis, Parkinson's, Alzheimer's and muscular dystrophy. Repeated long term exposure of some metals and their compounds may cause cancer. Also, RBCs count declines in fish subjected to higher concentration of endosulfan. It has also been postulated that the reduction of RBCs count might be due to inhibition of RBCs production and destruction of RBCs by pollutants ${ }^{1}$.

\section{Copper:-}

Copper is a trace element which is essential for the function of specific protein enzymes. However, at high concentrations it is toxic to the organisms. The increasing industrial activities and the use of $\mathrm{CuSO}_{4}$ as a fungicide in agricultural practices as well as in the control of algae and pathogens in fish culture ponds have increased the copper concentrations in aquatic systems. It is used in combination with lime and water as a protective agent ${ }^{3}$. Copper sulphate is very toxic to fish. Its toxicity to fish varies with the species and the physical and chemical characteristics of the water?.

\section{Nickel:-}

Nickel finds numerous applications in many industries because of its resistance to corrosion, high strength and durability, pleasing appearance, good thermal and electrical conductivity and its ability in forming alloys with other metals. The production of alloys accounts for approximately $75 \%$ of total nickel consumption ${ }^{6,7,10}$. The pathogenesis of nickel toxicity is relatively complex because of the large number of chemical and physical forms.

\section{Zinc:-}

Zinc, an essential trace metal which becomes toxic when it's concentration crosses the threshold limit in the nutritional supply. The main uses of zinc are in the manufacture of galvanized iron, bronze, white paint, rubber, glazes, enamel glass, paper, as a wood preservative ( $\mathrm{ZnCl} 2$, fungicidal action), petrochemicals, and fertilizers and in steam generation power plants ${ }^{6}$. Zinc, in lesser amount is released into the environment by natural processes, but heavier pollution is due to activities like mining, steel production, coal burning, and burning of waste. Zinc attaches to soil, sediments, and dust particles in the air. Zinc compounds can move into the groundwater and into lakes, streams, and rivers. Most of the zinc in soil stays bound to soil particles. Moderately increased zinc concentrations in water also stem from the release of zinc from drainage pipes due to corrosion. This ultimately accumulates in fish and other aqua organisms ${ }^{4}$.

\section{Cobalt:-}

Cobalt is found in meteorites. Elemental cobalt is a hard, silvery grey metal. However, cobalt is usually found in the environment combined with other elements such as oxygen, sulfur, and arsenic. Small amounts of these chemical compounds can be found in rocks, soil and plants, Cobalt metal is usually mixed with other metals to form alloys, these alloys are used in a number of military and industrial applications such as aircraft engines, magnets, and grinding and cutting tools. Cobalt compounds are used as colorants in glass, ceramics, and paints, as catalysts, and as paint driers. Cobalt colorants have a characteristic blue color; however, not all cobalt compounds are blue. Cobalt compounds are also used as trace element additives in agriculture and medicine.

\section{Cadmium:-}

This metal was first used in World War I as a substitute for tin. About $75 \%$ of the industrial consumption of Cadmium is attributed in the manufacturing of electrode components in alkaline batteries. Other industrial applications are in the production of rechargeable batteries, for production of special alloys, and are also present in tobacco smoke. It also finds wide applications in paint industries as a pigment. It is used in coatings, and also in plating works and also as a plastic stabilizer. Humans are exposed to this metal primarily by inhalation and ingestion and can suffer from acute and chronic intoxication.

\section{Effect of Heavy Metals on Human Health:-}

There are 35 different metals that are of great concern for human beings during residential or occupational exposure, out of which 23 are heavy metals, which are antimony, arsenic, bismuth, cadmium, cerium, chromium, cobalt, copper, gallium, gold, iron, lead, manganese, mercury, nickel, platinum, silver, tellurium, thallium, tin, uranium, 
vanadium, and zinc ${ }^{5}$. These heavy metals are commonly found in the environment and diet. In small amounts they are required for maintaining good health, but when in excess they can become toxic or dangerous. As discussed earlier, heavy metal toxicity can lower energy levels and damage the functioning of the vital organs of our body.

\section{Effect of Heavy Metals on Aquatic Life:-}

Fish is high in Omega-3 and protein content which is essential for a healthy human body. However, potentially dangerous heavy metals are absorbed into the body tissues of fish that are transferred to humans on consumption of this affected fish. Good quality of food for human consumption can only be produced in an environment free from contamination and pollution. Fish are of great economic importance, but are affected immensely by various chemicals including heavy metals directly or indirectly in different ways. Several reports indicate high mortality of juvenile fish and reduced breeding potential of adults after long term exposure to heavy metals ${ }^{\mathbf{8}}$. Freshwater fish Labeo rohita is of great commercial importance because it is the most common fish widely consumed worldwide. Therefore, it can be a good model to study the responses to heavy metal contaminations. Histopathological studies on fish are a noteworthy and promising field to understand the structural organizationoccurs in the organs due to pollutants in the environment. These structural changes vary with the body parts, nature of the pollutant, medium and duration of exposure. Water quality characteristics also influence histopathological manifestations of toxic effects $^{2}$. The structural changes in the organs at microscopic cellular and organ level leads to alterations of the function systems. Hence the main objective of this study is to provide insight into the source of heavy metals and their harmful effects on environment and living organisms.

\section{Methodology:-}

Processing of the fresh water fingerlings major carp Labeo rohita for the study:-

1. Live and healthy fresh water fingerlings major carp Labeo rohita of both sexes were collected from the local fish farms and kept as stock in Oxygen saturated water at appropriate $\mathrm{pH}$.

2. Commercial fish food was given twice a day.

3. The fish were acclimatized to the laboratory conditions for a period of 15-20 days.

4. Different concentration in ppm of Zinc, Cadmium, Copper, Nickel and Cobalt were prepared by dissolving appropriate amount of analytical grade Zinc chloride, Cadmium chloride, Copper chloride, Nickel sulphate and Cobalt sulphate in fresh water.

5. Amino acids were separated from the fish tissue using a centrifuge.

6. For qualitative and quantitative analysis of amino acids, 2-D ascending paper chromatographic technique was used.

7. Live and healthy fresh water fingerlings exposed to different concentrations of Zinc chloride, Cadmium chloride, Copper chloride, Nickel sulphate and Cobalt sulphate.

8. After exposing to different concentration and duration, 2-3 fingerlings were removed for blood smear study.

9. The thin blood smears were prepared for observing the cellular alterations in the blood cells. The smears were stained with Leishmann's stain and the observations were noted.

\section{Results AndDiscussion:-}

\section{Hematological Studies:-}

Effect of varying concentrations of heavy metal salts on normal blood cells of fish Labeo rohita exposed for 15, 30 and 45 days was studied. Following physiological changes in the fish were observed:

1. Cell membrane may be wrinkled, damaged or even totally destroyed.

2. Nucleus of the cell may be damaged.

3. Nucleus may shift in position.

4. Size of nucleus may be reduced or enlarged.

5. Nucleus may be totally destroyed.

6. Vacullation is observed inside the cell. 


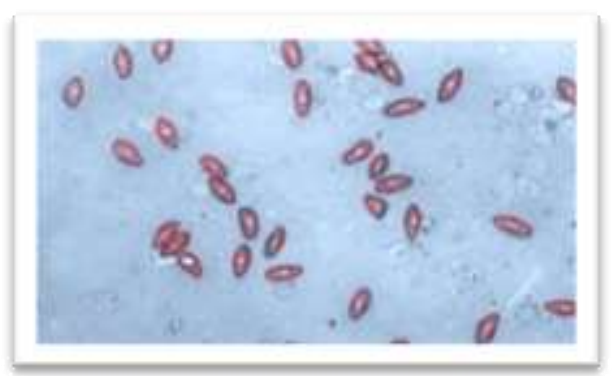

Normal blood smears of fish Labeorohita.

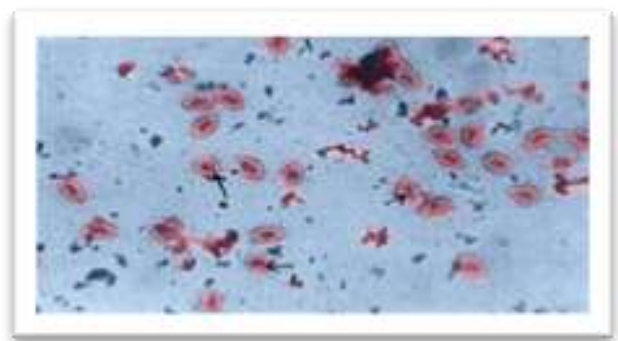

Cell membrane wrinkled and damaged.

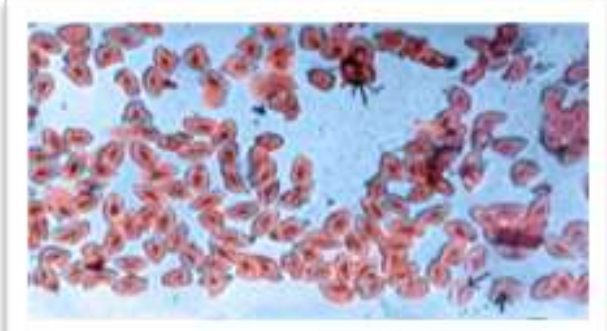

Size of the nucleus is reduced or enlarged.

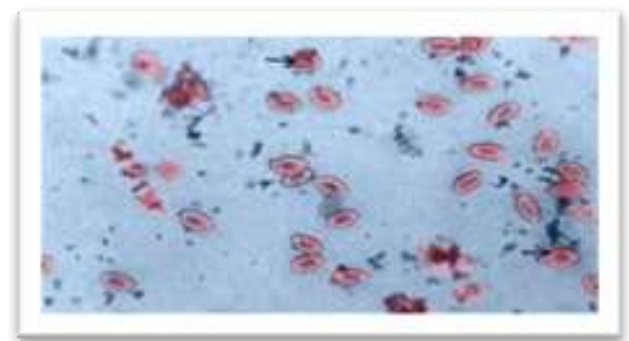

Nucleus shifts in position.

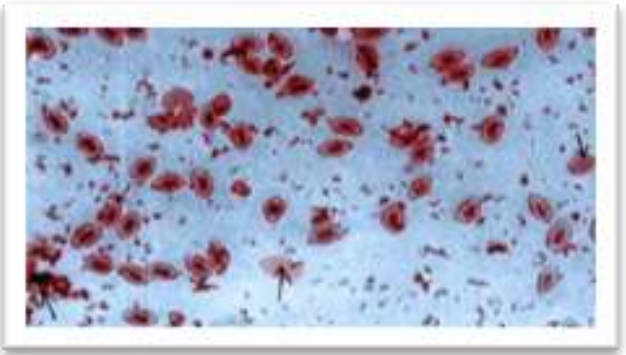

Vacullation is observed inside the cell.

Result of physiological changes due to the effect of heavy metal on fish Labeo rohita:-

Optical density change of different amino acids subjected to varying concentrations in ppm of heavy metal salts was observed.

1. In case of Chlorides of Copper, Zinc, and Cadmium; amino acids like Valine, Histidine, Proline, Glycine, Alanine and Methionine were found to be declining.

2. In case of Sulphate of Nickel and Cobalt, amino acids like Leucine, Proline, Glycine and Aspartic acid showed a tremendous decrease in amount.

3. The results clearly indicate the decrease of protein content in fish and all aquatic animals. 

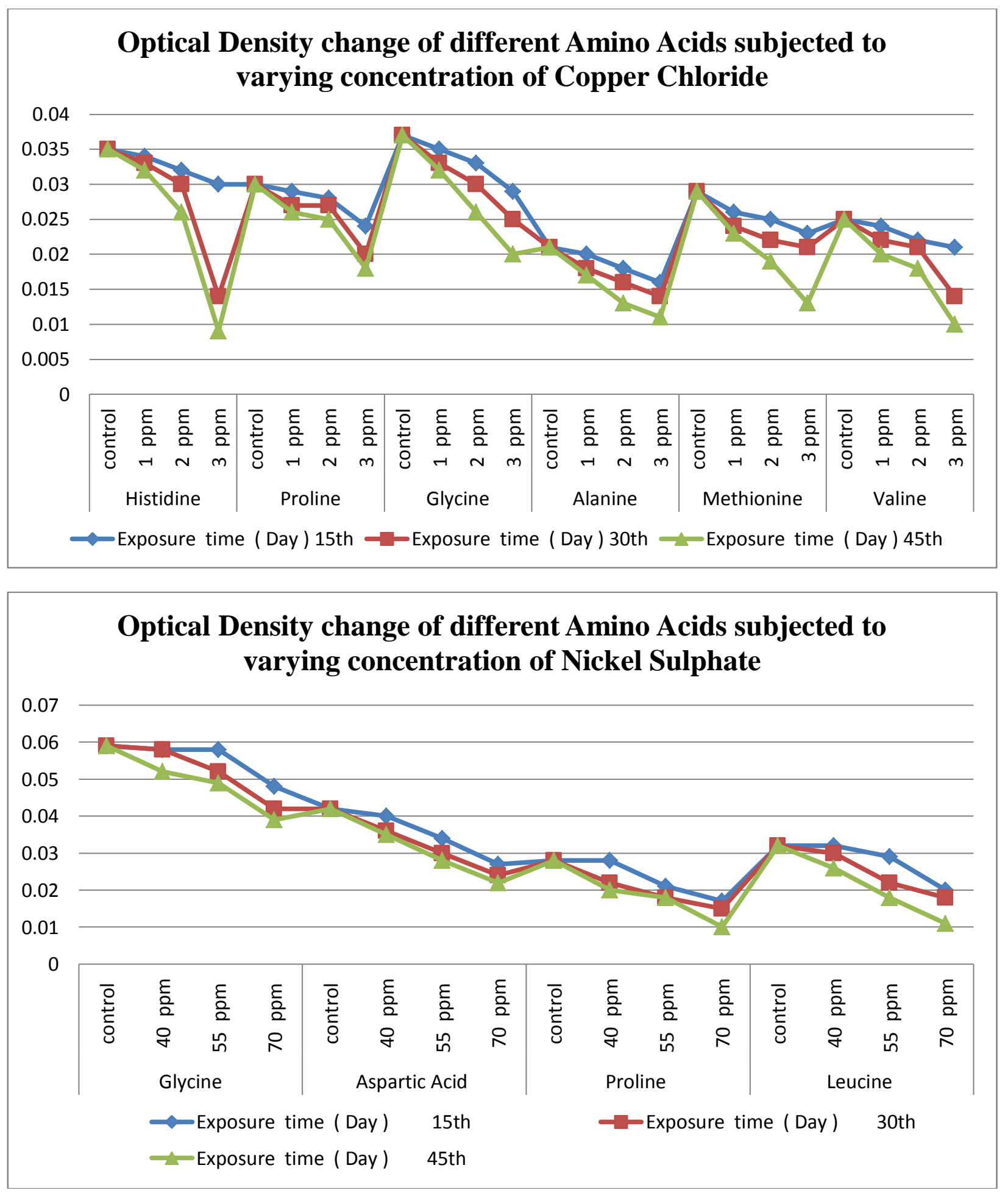

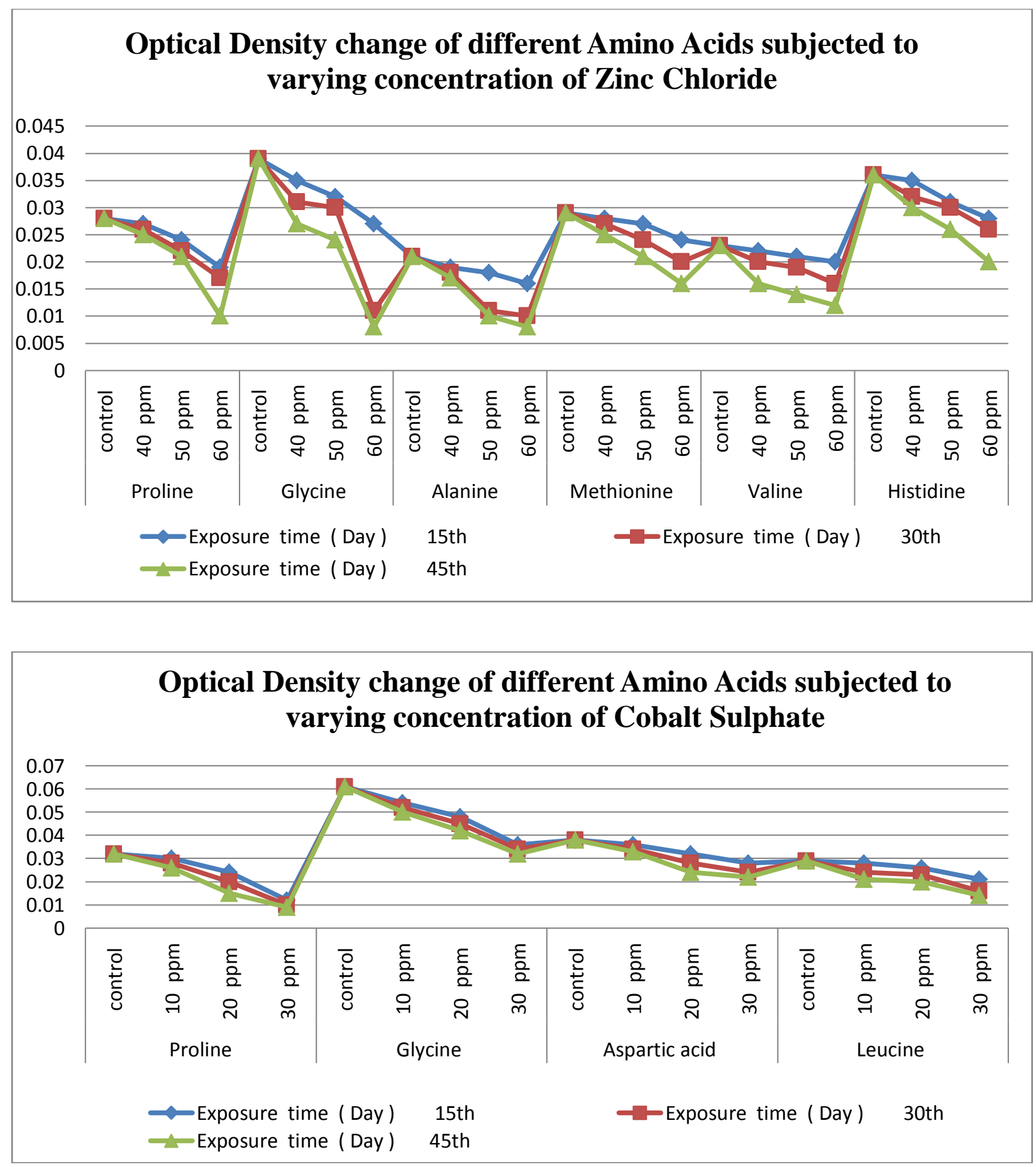


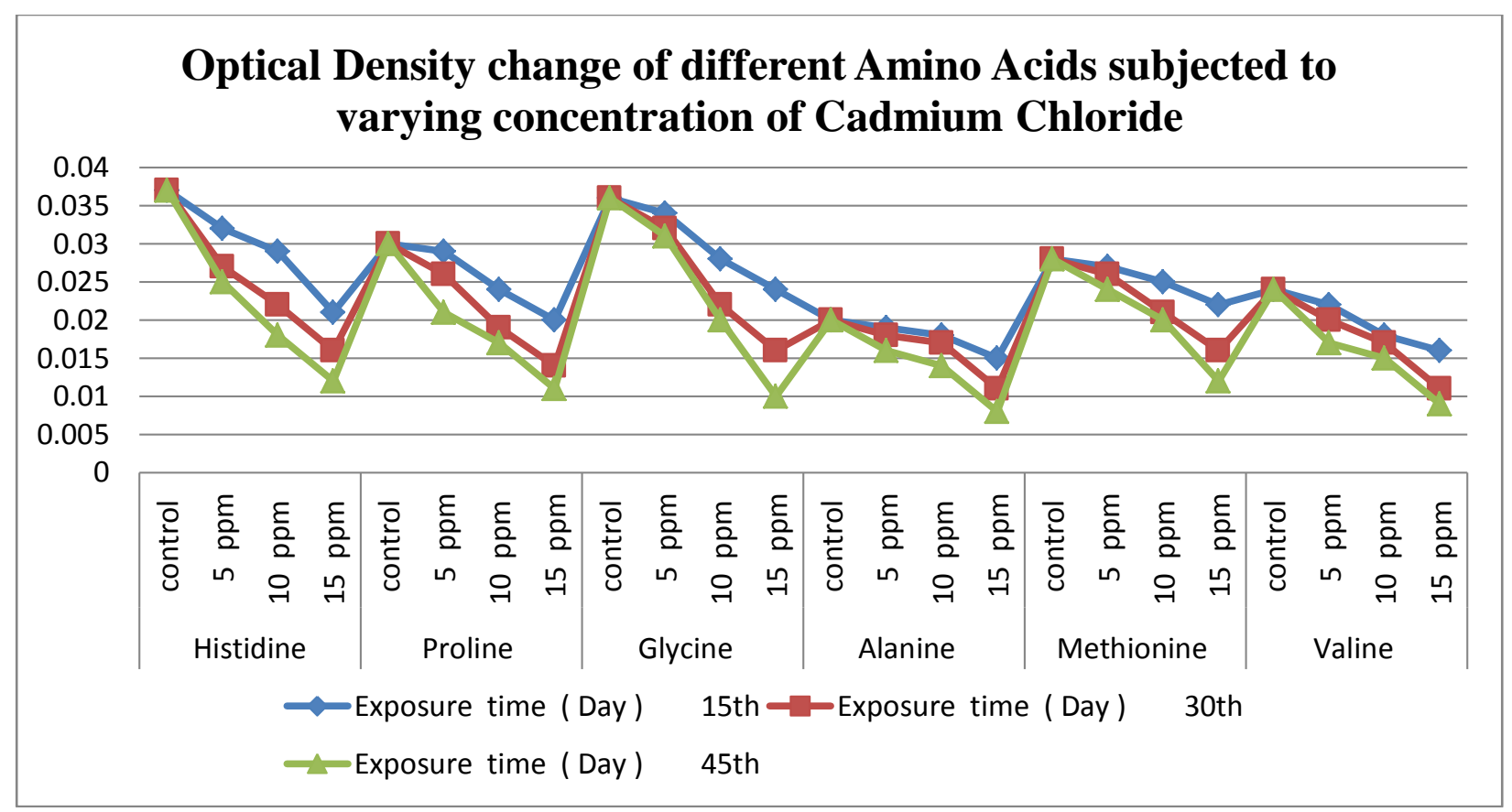

\section{Conclusion:-}

Heavy metal pollution leads to wrinkled cell membrane, damaged or enlarged nucleus and vacullation in aquatic life, leading to anemic condition of animals and or ultimate death on the long run. Anemic conditions and less iron content have been reported in fish, bird and mammals following their exposure to pollutants by several researchers. Protein deficiency in a human body leads to a number of health related problems, including reduction of chondroblastic and osteoblastic activity. This leads to an acute situation where the normal growth and formation of the bones and the cartilage gets hampered, which finally results in irreparable deformities in body of the growing children, and also in adults. Fish is the staple food of the people of coastal region in India. Hence it is a matter of utmost importance to study and constantly monitor the various heavy metal pollutants in water in and around the coastal region over the Globe as Humans consuming the affected fish suffers damage to liver, kidney, heart, bodyjoints. The liver and kidneys produce metallothioneins causing toxicity which is hazardous to human life.After this study of the effects of heavy metals on the environment and living organisms, mainly human beings, effective legislation, guidelines and detection of the areas where there are higher levels of heavy metals are necessary. Failure to control the exposure will result in severe complications in the future because of the adverse effects caused by heavy metals. Occupational exposure to heavy metals can be decreased by engineering solutions. Monitoring the exposure and probable intervention for reducing additional exposure to heavy metals in the environment and in humans can become a major step towards prevention. National as well as international co-operation is vital for framing appropriate laws to prevent heavy metal toxicity.

\section{Bibliography:-}

1. Anusha (1994); Effect of endosulfan on oxygen consumption, red blood cell count and food utilization of fresh water fish Clariusdussumieri; J. Environ. Toxicol., 4(1): 1-63, 33-36.

2. Galat, DL, Post G, Kerfe TJ, Boucks GR (1985); Histopathological changes in the gill, kidney and liver of Lohonta cut throat trout, salmoclarkiHenshawi, living in lakes of different salinityalkalinity; J.Fish. Biol. 27, 533-552.

3. Hayes WJ (1982); Pesticides studied in man. Baltimore, MD: Williams and Wilkins.

4. Joshi HC (1990); Environmental constrains in management of fisheries in open water system; Proceedings of the National Seminar on Management of fisheries in Inland open water system of India, Barracpore. West Bengal India. Dec. 1988, 23-30.

5. Mosby CV, Glanze WD, Anderson KN (1996); Mosby Medical Encyclopedia,The Signet: Revised Edition. St. Louis.

6. Nicolaidou A, Nott J (1989); Heavy metal pollution induced by ferronickel smelting plant in Greece; Sci. of the Total Environ. 84, 113-117. 
7. Nriagu JO, Pacyna JM (1988); Quantitative assessment of worldwide contamination of air, water and soils by trace metals; Nature 333: 134-139.

8. Olojo EAA, Olurin KB, Mbaka, Oluwemimo AD (2005); Histopathology of gill and liver tissue of the african catfish Clariasgariepinus exposed to lead; African J. Biotechnol. 4(1): 117-122.

9. Toxne T (1975-1986); National library of medicine's toxicology data network. Hazardous Substances Data Bank (HSDB). Public Health Service. National Institute of Health, U. S. Department of Health and Human Services. Bethesda, MD: NLM.

10. Wilson BL, Schwarzer RR, Etonyeaku N (1986); The evaluation of heavy metals (Cr, Ni and Co) in the aqueous sediment surrounding a coal burning generating plant; J. Enviorn. Sci. Health, 21, 791-808. 